\title{
Lipase-Catalyzed Synthesis of Ascorbyl Oleate in Acetone: Optimization of Reaction Conditions and Lipase Reusability
}

\author{
Marija Stojanović ${ }^{1}$, Dušan Veličković ${ }^{2}$, Aleksandra Dimitrijević ${ }^{2}$, Nenad Milosavić ${ }^{2}$ \\ Zorica Knežević-Jugović ${ }^{1}$ and Dejan Bezbradica ${ }^{1 *}$ \\ ${ }^{1}$ Department of Biochemical Engineering and Biotechnology, Faculty of Technology and Metallurgy, University of Belgrade, Karnegijeva 4, \\ 11000 Belgrade, Serbia \\ ${ }^{2}$ Department of Biochemistry, Faculty of Chemistry, University of Belgrade, Studentski trg 12, 11000 Belgrade, Serbia
}

\begin{abstract}
Lipase-catalyzed ascorbyl oleate synthesis is eco-friendly and selective way of production of liposoluble biocompatible antioxidants, but still not present on an industrial level due to the high biocatalyst costs. In this study, response surface methodology was applied in order to estimate influence of individual experimental factors, identify interactions among them, and to determine optimum conditions for enzymatic synthesis of ascorbyl oleate in acetone, in terms of limiting substrate conversion, product yield, and yield per mass of consumed enzyme. As a biocatalyst, commercial immobilized preparation of lipase B from Candida antarctica, Novozym 435 , was used. In order to develop cost-effective process, at reaction conditions at which maximum amount of product per mass of biocatalyst was produced $\left(60^{\circ} \mathrm{C}, 0.018 \%(\mathrm{v} / \mathrm{v})\right.$ of water, $0.135 \mathrm{M}$ of vitamin $\mathrm{C}$, substrates molar ratio $1: 8$, and $0.2 \%$ (w/v) of lipase), possibilities for further increase of ester yield were investigated. Addition of molecular sieves at $4^{\text {th }}$ hour of reaction enabled increase of yield from $16.7 \mathrm{mmol} \mathrm{g}^{-1}$ to $19.3 \mathrm{mmol} \mathrm{g}^{-1}$. Operational stability study revealed that after ten reaction cycles enzyme retained $48 \%$ of its initial activity. Optimized synthesis with well-timed molecular sieves addition and repeated use of lipase provided production of $153 \mathrm{mmol}$ per gram of enzyme. Further improvement of productivity was achieved using procedure for the enzyme reactivation.
\end{abstract}

Key words: Candida antarctica lipase B, vitamin C, oleic acid, optimization, ascorbyl oleate

\section{INTRODUCTION}

Deterioration of lipid-rich food and cosmetic products due to lipid autooxidation is main obstacle for their wider application. At present, synthetic antioxidants such as BHT (butylated hidroxytoluene) and BHA (butylated hidroxyanisole) are being used to prevent oxidation of lipids in these products, but their application is questionable because of their potential toxicity ${ }^{1}$. Natural antioxidants which could be used as adequate substitute for this purpose are fatty acid esters of vitamin C, since they are lipophilic (in distinction to vitamin $\mathrm{C}$ ), their free radical scavenging capacity is high, their usage does not pass on any additional odor, flavor, and color to the product, and their degradation forms are not toxic (unlike synthetic antioxidants) ${ }^{1-3)}$. Additionally, fatty acid ascorbyl esters are compounds with both hydrophobic and hydrophilic functionality and therefore can be used as non-ionic surfactants in detergents, food, cosmetics, pharmaceuticals, textiles, and paper. These surfactants are renewable and eco-friendly, which makes them more suitable for use comparing to those obtained from petrochemical resources ${ }^{4)}$. Owing to their amphiphilic nature, fatty acid ascorbyl esters form in water supramolecular structures with a lipophilic core and a hydrophilic outer part ${ }^{5}$. That fact was used in the research carried out by Moribe et al., focused on drug nano-particles formulations ${ }^{6}$. Nowadays, efforts are being made in order to develop industrial process for enzymatic synthesis of vitamin $\mathrm{C}$ fatty acid esters, considering numerous advantages over conventional chemical methods, such as mild reaction conditions, high catalytic efficiency and selectivity, and simplified downstream processing if immobilized enzyme is used ${ }^{3)}$.

Lipases (triacylglycerol acyl-hydrolases, E.C. 3.1.1.3.) gain huge interest of researchers due to their ability to cat-

\footnotetext{
*Correspondence to: Dejan Bezbradica, Department of Biochemical Engineering and Biotechnology, Faculty of Technology and Metallurgy, Karnegijeva 4, 11000 Belgrade, Serbia

E-mail: dbez@tmf.bg.ac.rs

Accepted March 5, 2013 (received for review January 18, 2013)

Journal of Oleo Science ISSN 1345-8957 print / ISSN 1347-3352 online

http://www.jstage.jst.go.jp/browse/jos/ http://mc.manusriptcentral.com/jjocs
} 
alyze wide range of reactions, including esterification at hydrophobic/hydrophilic interfaces ${ }^{7-9)}$. In recent years enzymatic synthesis of ascorbyl esters has been reported, in which several microbial lipases, such as lipase from Candida antarctica type B, lipase from Thermomyces lanuginosus, Bacillus stearothermophylus SB1 lipase, and lipase from Rhizomucor miehei, were successfully used as biocatalysts ${ }^{2,10-15)}$. Majority of reported investigations were focused on esterification with saturated acids, mainly palmitic acid ${ }^{3,10-13}$. However, relatively low solubility of ascorbyl palmitate in oils is main obstacle for its wider application in food. This drawback could be overcome by using unsaturated acyl donors. Nowadays enzymatic synthesis of ascorbyl oleate and other ascorbyl esters of unsaturated fatty acids are very attractive, especially since it was reported that ascorbyl oleate has stronger antioxidative activity in comparison with ascorbyl palmitate and vitamin $\mathrm{C}^{13)}$. In the present, majority of investigations devoted to ascorbyl oleate synthesis, describe reaction in $t$ butanol or $t$-amyl alcohol as organic solvents ${ }^{13,14,16)}$. As alternative solvents, ionic liquids (IL) were used, due to the good solubility of reactants and products ${ }^{17,18)}$. When it comes to acyl donors, both fatty acids and their methyl and vinyl esters were used in previous studies. Generally, higher yields were achieved when activated acyl donors were applied instead of oleic acid ${ }^{17,19)}$. In both cases costs of the process were significantly increased, and enzyme stability was called into question when ILs were used.

Conventional methods for the optimization of enzymatic reactions involve varying one parameter at a time while the others are kept constant which, in distinction to factorial design, does not provide insight into existence and nature of interactions among factors ${ }^{20)}$. Response surface methodology (RSM) and central composite rotatable design (CCRD) are useful statistical techniques for investigation and optimization of complex processes in which existence of interactions among experimental parameters is assumed. These methods have been successfully employed in researches focused on lipase-catalyzed esters production ${ }^{21,22)}$. Nevertheless, only in a few extensive studies RSM and CCD were applied for the optimization of enzymatic synthesis of fatty acid ascorbyl esters ${ }^{12,23,24,25)}$. In these studies influence of several important experimental parameters was investigated, but exclusively in terms of limiting substrate molar conversion. Also, to our best knowledge, esterification of oleic acid with vitamin C catalyzed by lipases was not by now optimized using any kind of statistical design.

In this study, the synthesis of ascorbyl oleate was catalyzed with immobilized lipase from $C$. antarctica and oleic acid was used as acyl donor, because of its low price and commercial availability. As a reaction medium acetone was applied, since there are previous reports of its successful application in biocatalyzed synthesis of ascorbyl oleate ${ }^{19)}$. Additionally, it has been rated as a GRAS (generally recog- nized as safe) substance in food and preserves at concentrations ranging from 5 to $8 \mathrm{mg} \mathrm{l}^{-1}$, while lower price and higher volatility makes it more economically favorable comparing to $t$-butanol, since high volatility offers possibility of less energy consuming and simpler downstream processing. Effects of key experimental factors (enzyme loading, vitamin C concentration, initial water content, substrate molar ratio, and temperature) on biosynthesis and interactions between them were analyzed using RSM and 5-level-5-factor CCRD. Examined parameters were optimized in terms of limiting substrate conversion, ester yield, and yield of product relative to immobilized lipase amount. Also, the attempt was made to increase product yield by addition of molecular sieves, in order to absorb water produced during esterification, and timing of sieve addition was optimized. Finally, the reuse of immobilized catalyst utilized at optimum conditions was tested throughout ten reaction cycles and different reactivation strategies were tested.

\section{EXPERIMENTAL PROCEDURES}

\subsection{Enzyme and chemicals}

Novozym $^{\boxplus} 435$ (lipase from C. antarctica, type B immobilized on acrylic resin) was purchased from Novozymes (Bagsvaerd, Denmark). Substrates were L-ascorbic acid (purity 99.7\%, Zorka, Šabac, Serbia) and oleic acid (Ph. Eur., NF pure) purchased from Appli Chem, Darmstadt, Germany. As reaction media, acetone $(99.5 \%$, Zorka Pharma, Šabac, Serbia)was used. Substances used for the quantitative HPLC (high performance liquid chromatography) analyses were methanol obtained from JT Baker, SAD, and phosphoric acid purchased from Sigma-Aldrich Chemie Gmbh, all of HPLC grade. Zeolite molecular sieves with diameter 2-3 $\mathrm{mm}$ and $0.4 \mathrm{~nm}$ pores were used as water adsorbents. Acetonitrile and formic acid (mobile phase for reaction product purification) were of HPLC purity, both purchased from Sigma-Aldrich Chemie Gmbh. For the spectral analysis, 2,2-dimethyl-2-silapentane-5-sulfonate sodium salt and $\mathrm{CDCl}_{3}$ were used (HPLC grade, Sigma-Aldrich Chemie Gmbh).

\subsection{Procedure for the enzymatic synthesis}

Experiments were carried out in $100 \mathrm{~mL}$ capped vessels. The reaction mixture consisted of different amounts of ascorbic acid, oleic acid, enzyme, water, and acetone (amounts specified for each experiment separately), so that the total volume was $10 \mathrm{~mL}$. The measurement of water concentration in organic solvent was performed on the Karl-Fischer apparatus (Mettler Toledo, USA).

The reactions were conducted in a shaker at $250 \mathrm{rpm}$ and at temperature in range from 40 to $60^{\circ} \mathrm{C}$. Reaction time was $72 \mathrm{~h}$. All experiments were carried out in duplicate 
and average values are presented in following figures. All standard deviations were less than 5\%. Control samples (without enzyme)were prepared by exposure to the same temperature treatment. Product was not determined in control samples.

\subsection{Experimental design and statistical analysis}

A 5-level-5-factor CCRD, including 32 experimental points (16 factorial, 10 axial, and 6 center points)was employed in this study. Table 1 shows experimental design (coded and actual levels of variables) and obtained results. All 32 runs were performed in random order so that the systematic errors would be avoided.

Experimental data were analyzed by response surface regression (RSREG) method to fit the second-order polynomial equation

$$
Y=\beta_{k 0}+\Sigma_{i=1}^{5} \beta_{k i} X_{i}+\Sigma_{i=1}^{5} \beta_{k i i} X_{i}^{2}+\Sigma_{i=1}^{4} \Sigma_{j=i+1}^{5} \beta_{k i j} X_{i} X_{j}
$$

Where $Y$ is response (conversion $\left(Y_{1}\right)$, yield $\left(Y_{2}\right)$, and yield of product per enzyme amount $\left.\left(Y_{3}\right)\right), \beta_{k 0}, \beta_{k i}, \beta_{k i i}$, and $\beta_{k i j}$ are constant regression coefficients, $X_{i}$ and $X_{j}$ are uncoded independent variables, and $k$ is the number of single factor. The least square method was employed for the response function coefficients calculation and their statistical significance evaluation. MATLAB 7.0 (Mathworks Inc., Natick, MA, USA) was used for that purpose. Only the significant terms $(p \leq 0.05)$ were considered for the final reduced model. Adequacy of the obtained model was tested using the Fisher test. Student distribution was used to evaluate the significance of the coefficients.

\subsection{Reusability study}

Experiments were conducted at previously optimized

Table 1 Experimental design and obtained results.

\begin{tabular}{|c|c|c|c|c|c|c|c|c|}
\hline Exp. & $\begin{array}{c}\text { Water } \\
\text { content } \\
X_{1} \\
{[\%(\mathrm{v} / \mathrm{v})]}\end{array}$ & $\begin{array}{c}\text { Temperature } \\
X_{2} \\
{\left[{ }^{\circ} \mathrm{C}\right]}\end{array}$ & $\begin{array}{c}\text { Enzyme } \\
\text { amount } \\
X_{3} \\
{[\%(\mathrm{w} / \mathrm{v})]}\end{array}$ & $\begin{array}{c}\text { Substrates } \\
\text { molar ratio } \\
X_{4}\end{array}$ & $\begin{array}{c}\text { Vitamin } \mathrm{C} \\
\text { concentration } \\
X_{5} \\
{[\mathrm{M}]}\end{array}$ & $\begin{array}{c}\text { Conversion } \\
Y_{1} \\
{[\%]}\end{array}$ & $\begin{array}{c}\text { Yield } \\
Y_{2} \\
{[\mathrm{mM}]}\end{array}$ & $\begin{array}{c}\text { Yield } \\
Y_{3} \\
{\left[\mathrm{mmol} \mathrm{g}^{-1}\right]}\end{array}$ \\
\hline 1 & $0.168(1)$ & $55(1)$ & $0.8(1)$ & $1: 12(1)$ & $0.17(1)$ & 13.89 & 23.62 & 2.95 \\
\hline 2 & $0.168(1)$ & $55(1)$ & $0.8(1)$ & $1: 6(-1)$ & $0.07(-1)$ & 35.90 & 25.13 & 3.14 \\
\hline 3 & $0.168(1)$ & $55(1)$ & $0.4(-1)$ & $1: 12(1)$ & $0.07(-1)$ & 44.05 & 30.83 & 7.70 \\
\hline 4 & $0.168(1)$ & $55(1)$ & $0.4(-1)$ & $1: 6(-1)$ & $0.17(1)$ & 18.22 & 30.97 & 7.74 \\
\hline 5 & $0.168(1)$ & $45(-1)$ & $0.8(1)$ & $1: 12(1)$ & $0.07(-1)$ & 32.35 & 22.65 & 2.83 \\
\hline 6 & $0.168(1)$ & $45(-1)$ & $0.8(1)$ & $1: 6(-1)$ & $0.17(1)$ & 11.53 & 19.60 & 2.44 \\
\hline 7 & $0.168(1)$ & $45(-1)$ & $0.4(-1)$ & $1: 12(1)$ & $0.17(1)$ & 7.41 & 12.59 & 3.14 \\
\hline 8 & $0.168(1)$ & $45(-1)$ & $0.4(-1)$ & $1: 6(-1)$ & $0.07(-1)$ & 29.79 & 20.85 & 5.21 \\
\hline 9 & $0.068(-1)$ & $55(1)$ & $0.8(1)$ & $1: 12(1)$ & $0.07(-1)$ & 56.97 & 39.88 & 4.98 \\
\hline 10 & $0.068(-1)$ & $55(1)$ & $0.8(1)$ & $1: 6(-1)$ & $0.17(1)$ & 22.78 & 38.71 & 4.83 \\
\hline 11 & $0.068(-1)$ & $55(1)$ & $0.4(-1)$ & $1: 12(1)$ & $0.17(1)$ & 16.44 & 27.94 & 6.98 \\
\hline 12 & $0.068(-1)$ & $55(1)$ & $0.4(-1)$ & $1: 6(-1)$ & $0.07(-1)$ & 48.96 & 34.27 & 8.56 \\
\hline 13 & $0.068(-1)$ & $45(-1)$ & $0.8(1)$ & $1: 12(1)$ & $0.17(1)$ & 9.35 & 15.90 & 1.98 \\
\hline 14 & $0.068(-1)$ & $45(-1)$ & $0.8(1)$ & $1: 6(-1)$ & $0.07(-1)$ & 30.12 & 21.09 & 2.63 \\
\hline 15 & $0.068(-1)$ & $45(-1)$ & $0.4(-1)$ & $1: 12(1)$ & $0.07(-1)$ & 44.77 & 31.34 & 7.83 \\
\hline 16 & $0.068(-1)$ & $45(-1)$ & $0.4(-1)$ & $1: 6(-1)$ & $0.17(1)$ & 20.12 & 34.20 & 8.54 \\
\hline 17 & $0.218(2)$ & $50(0)$ & $0.6(0)$ & $1: 9(0)$ & $0.12(0)$ & 21.77 & 26.13 & 4.35 \\
\hline 18 & $0.018(-2)$ & $50(0)$ & $0.6(0)$ & $1: 9(0)$ & $0.12(0)$ & 31.65 & 37.98 & 6.33 \\
\hline 19 & $0.118(0)$ & $60(2)$ & $0.6(0)$ & $1: 9(0)$ & $0.12(0)$ & 32.16 & 38.59 & 6.43 \\
\hline 20 & $0.118(0)$ & $40(-2)$ & $0.6(0)$ & $1: 9(0)$ & $0.12(0)$ & 27.99 & 33.59 & 5.59 \\
\hline 21 & $0.118(0)$ & $50(0)$ & $1(2)$ & $1: 9(0)$ & $0.12(0)$ & 25.09 & 30.11 & 3.01 \\
\hline 22 & $0.118(0)$ & $50(0)$ & $0.2(-2)$ & $1: 9(0)$ & $0.12(0)$ & 25.28 & 30.33 & 15.2 \\
\hline 23 & $0.118(0)$ & $50(0)$ & $0.6(0)$ & $1: 15(2)$ & $0.12(0)$ & 18.64 & 22.37 & 3.72 \\
\hline 24 & $0.118(0)$ & $50(0)$ & $0.6(0)$ & $1: 3(-2)$ & $0.12(0)$ & 17.18 & 20.62 & 3.43 \\
\hline 25 & $0.188(0)$ & $50(0)$ & $0.6(0)$ & $1: 9(0)$ & $0.22(2)$ & 9.24 & 20.42 & 3.40 \\
\hline 26 & $0.118(0)$ & $50(0)$ & $0.6(0)$ & $1: 9(0)$ & $0.02(-2)$ & 35.29 & 7.06 & 1.17 \\
\hline 27 & $0.118(0)$ & $50(0)$ & $0.6(0)$ & $1: 9(0)$ & $0.12(0)$ & 23.93 & 28.72 & 4.78 \\
\hline 28 & $0.118(0)$ & $50(0)$ & $0.6(0)$ & $1: 9(0)$ & $0.12(0)$ & 28.17 & 33.81 & 5.63 \\
\hline 29 & $0.118(0)$ & $50(0)$ & $0.6(0)$ & $1: 9(0)$ & $0.12(0)$ & 27.56 & 33.07 & 5.51 \\
\hline 30 & $0.118(0)$ & $50(0)$ & $0.6(0)$ & $1: 9(0)$ & $0.12(0)$ & 25.84 & 31.01 & 5.16 \\
\hline 31 & $0.118(0)$ & $50(0)$ & $0.6(0)$ & $1: 9(0)$ & $0.12(0)$ & 22.93 & 27.51 & 4.59 \\
\hline 32 & $0.118(0)$ & $50(0)$ & $0.6(0)$ & $1: 9(0)$ & $0.12(0)$ & 29.17 & 35.01 & 5.83 \\
\hline
\end{tabular}


reaction conditions. After each reaction cycle (24 hours), samples were taken for HPLC analysis and the enzyme was separated from the remaining reaction mixture by vacuum filtration. Immobilized lipase was then washed-out three times with $20 \mathrm{~mL}$ of acetone, dried at $37^{\circ} \mathrm{C}$ for 3 hours, and reused in the following cycle. Ten consecutive reaction cycles were performed.

Enzyme, remained after reusability study, was reactivated during the 30 minutes long treatment in a shaker at 100 $\mathrm{rpm}$ and $25^{\circ} \mathrm{C}$. As a reactivating agent, $10 \mathrm{~mL}$ of $0.05 \mathrm{M}$ sodium phosphate buffer has been used.

\subsection{HPLC analysis}

For quantitative analysis of reactants and products, Akta Purifier HPLC system (Amersham Pharmacia Biotech, Piscataway, NJ, USA) was used. A reverse phase column, Waters Spherisorb ODS 2-C18, $250 \mathrm{~mm} \times 4.6 \mathrm{~mm}, 5 \mu \mathrm{m}$, was employed (Waters, Milford, MA, USA). Injection volume of reaction mixture, fifteen times diluted, was 10 $\mu \mathrm{L}$. Methanol $/ \mathrm{H}_{3} \mathrm{PO}_{4}, 100 / 0.1(\mathrm{v} / \mathrm{v})$, was used as eluent with a flow rate of $1 \mathrm{~mL} \mathrm{~min}^{-1}$. Product was detected by UV detector at $235 \mathrm{~nm}$.

\subsection{Purification of reaction product}

Reaction mixture was filtered, evaporated under reduced pressure and diluted in acetonitrile to reach one tenth of concentration in reaction mixture. Diluted mixture was subjected to Akta Purifier HPLC system equipped with fraction collector. Semi preparative reversed-phase C18 column (HYPERSIL GOLD $5 \mu \mathrm{m}$ ODS, $10 \times 250 \mathrm{~mm}$, Thermo Fisher Scientific, Waltham, MA, USA) that has been preconditioned with $95 \%$ acetonitrile in $0.1 \%(\mathrm{v} / \mathrm{v})$ formic acid, was used. The injection volume was $1 \mathrm{~mL}$. Mobile phase was $95 \%$ acetonitrile in $0.1 \%(\mathrm{v} / \mathrm{v})$ formic acid. The flow rate was $6 \mathrm{~mL} \mathrm{~min}{ }^{-1}$ while the detection wavelength was $235 \mathrm{~nm}$. The pick fractions $(0.5 \mathrm{~mL}$ volume) of product were collected by fraction collector. Fractions with pure compound (retested in analytical column) were merged and evaporated to constant mass.

\subsection{Spectral analysis}

NMR spectra were obtained on a Varian Gemini $200\left({ }^{1} \mathrm{H}\right.$ NMR at $200 \mathrm{MHz},{ }^{13} \mathrm{C} \mathrm{NMR}$ at $\left.50 \mathrm{MHz}\right)$, manufactured by Varian Medical Systems, Palo Alto, CA, USA. Chemical shifts were expressed in ppm ( $\delta$ ) using 2,2-dimethyl-2-silapentane-5-sulfonate sodium salt as an internal standard.

\section{RESULTS AND DISCUSSION}

The effects of five experimental factors were optimized with respect to different outputs, using RSM and CCRD. Further improvement of ascorbyl oleate synthesis was performed by optimization of water removal with molecular sieves and operational stability study.

\subsection{RSM optimization of key reaction factors}

RSM was used to evaluate significance of individual factors, recognize their interactive effects, and to determine optimum conditions for ascorbyl oleate synthesis. RSM has been applied previously in optimization of synthesis of ascorbyl esters of lauric, palmitic or benzoic acid ${ }^{12,24,25)}$, but to our best knowledge not with oleic acid or other unsaturated fatty acids as acyl-donors. Most importantly, in all related studies output variable was conversion degree of limiting substrate (ascorbic acid). In these studies, depending on nature of acyl donor, organic solvent, and ranges in which examined factors were varied, large discrepancies were obtained. For instance, temperatures in range 30.6$70^{\circ} \mathrm{C}$ were determined to be optimal, highest conversions were achieved using amounts of enzyme ranging from 0.18 to $1 \%(\mathrm{w} / \mathrm{v})$, and optimum substrates molar ratios were between 1:1 and 1:9. In our study, besides conversion degree, two additional outputs have been analyzed-product yield and specific product yield (per enzyme amount). In our opinion, these outputs provide additional information for process development. Product yield offers better insight into overall space productivity of reactor that should be taken into consideration, while specific product yield is more suitable output for optimization of economically sound enzymatic processes, since enzyme price predominantly contributes to overall production costs.

The effects of key reaction factors (temperature, enzyme input, initial water concentration, substrates molar ratio, and vitamin C concentration) were examined using 5-factor-5-level experimental design and obtained results are given in Table 1.

It is obvious even by rapid overview of obtained results that reaction factors exhibit different effect on examined variables. The highest conversion of limiting substrate $(57 \%)$ was achieved in exp. 9 performed at $0.118 \%$ of water, $55^{\circ} \mathrm{C}, 0.8 \%$ of lipase, substrates molar ratio $1: 12$, and $0.07 \mathrm{M}$ of ascorbic acid. High conversions were achieved in experiments 12,15 and 3 , which were performed at equal ascorbic acid concentration, indicating that high conversion degrees can be reached only at low ascorbic acid concentrations. Product yield also reached maximum in exp. 9, but similar yield was achieved in exp. 10 at higher initial ascorbic acid concentration. On the other hand, specific yield reached maximum in exp. 22 performed at $0.118 \%$ of water, $50^{\circ} \mathrm{C}, 0.2 \%$ of lipase, substrates molar ratio $1: 9$, and $0.12 \mathrm{M}$ of ascorbic acid. The most striking difference between experiments 9 and 22 is enzyme concentration, since specific yield reached maximum at lowest concentration.

Then, three outputs were fitted with model(Eq. 1)and adequacy of second order regression model was confirmed by Fisher test in all three cases. The significance of regres- 
sion model coefficients was tested using Student' s test and after exclusion of insignificant terms following models were obtained:

$$
\begin{aligned}
Y_{1}[\%]= & 26.17-3.17 X_{1}+3.34 X_{2}+0.45 X_{4}-10.6 X_{5}+ \\
& 0.737 X_{1}^{2}+1.58 X_{2}^{2}-1.47 X_{4}^{2}+1.33 X_{1} X_{5}- \\
& 1.63 X_{2} X_{5}-3.7 X_{5} X_{4} \\
Y_{2}[m M]= & 32.1-3.37 X_{1}+3.47 X_{2}+1.28 X_{2}^{2}-2.39 X_{4}^{2}- \\
& 4.34 X_{5}^{2}-4.19 X_{4} X_{5} \\
Y_{3}\left[\mathrm{mmol} \mathrm{g}^{-1}\right]= & 5.42-0.632 X_{1}+0.581 X_{2}-2.26 X_{3}- \\
& 0.172 X_{4}+0.008 X_{5}+0.918 X_{3}^{2}- \\
& 0.465 X_{4}^{2}-0.798 X_{5}^{2}+0.317 X_{1} X_{3}- \\
& 0.773 X_{4} X_{5}
\end{aligned}
$$

Observed discrepancies in output maximums are confirmed with regression models, since it can be observed that all examined factors exhibited effect on specific product yield (Eq. 4), while from models describing conversion of limiting substrate (Eq. 2) and product yield (Eq. 3) lipase concentration $\left(\mathrm{x}_{3}\right)$ was excluded because it was statistically insignificant. Also, models differ in intensity of individual factors effect and contribution of interaction terms, which will be explained in details in following sections.

3.1.1 The effect of initial water content

The concentration of water in reaction media is one of crucial factors which affect the enzymatic esterification. As it is known, certain amount of water needs to be present in reaction medium, since monomolecular layer of water on surface of enzyme molecule is necessary for enzyme activi$t^{26}{ }^{26}$. On the other hand, reaction equilibrium can, undesir- ably, be shifted towards ascorbyl oleate hydrolysis, both by initial and generated water. In our study initial water concentration was optimized within range $0.018-0.218 \%(\mathrm{v} / \mathrm{v})$, where lowest concentration is equal to water present in acetone.

Decrease of all of examined outputs with the increase of initial water concentration was observed(Fig. 1), since negative linear coefficient appears in each of regression models (Eq. 2-4).

According to previous studies, it seems that immobilized C. antarctica lipase contains sufficient amount of water for preservation of its catalytic activity, since it has been reported several times that it exhibited highest activity at very low concentrations of water in reaction mixtures or in completely anhydrous medium ${ }^{27-30}$. However, when RSM was applied in optimization of ascorbyl benzoate synthesis, maximum results were achieved at significantly higher initial water content, comparing to our results and results of majority of previous reserches ${ }^{25)}$. In our study, solvent of higher polarity was used, so it is plausible that certain amount of added water is needed because polar solvents can dissolve water layer around lipase molecule. Also, the interaction of water concentration with some of other factors was observed. For example, in substrate conversion model (Eq. 2) the positive interaction between water concentration $\left(\mathrm{x}_{1}\right)$ and ascorbic acid $\left(\mathrm{x}_{5}\right)$ was observed (Fig. 1), probably due to the fact that solubility of ascorbic acid in water is significantly higher than in acetone, hence this water layer can serve as pool of this substrate in vicinity of active site. On the other hand, positive interaction (Eq. 4, Fig. 2) between water concentration and enzyme concentration $\left(\mathrm{x}_{3}\right)$ can be ascribed to necessity of higher water concentration to provide formation of monomolecular

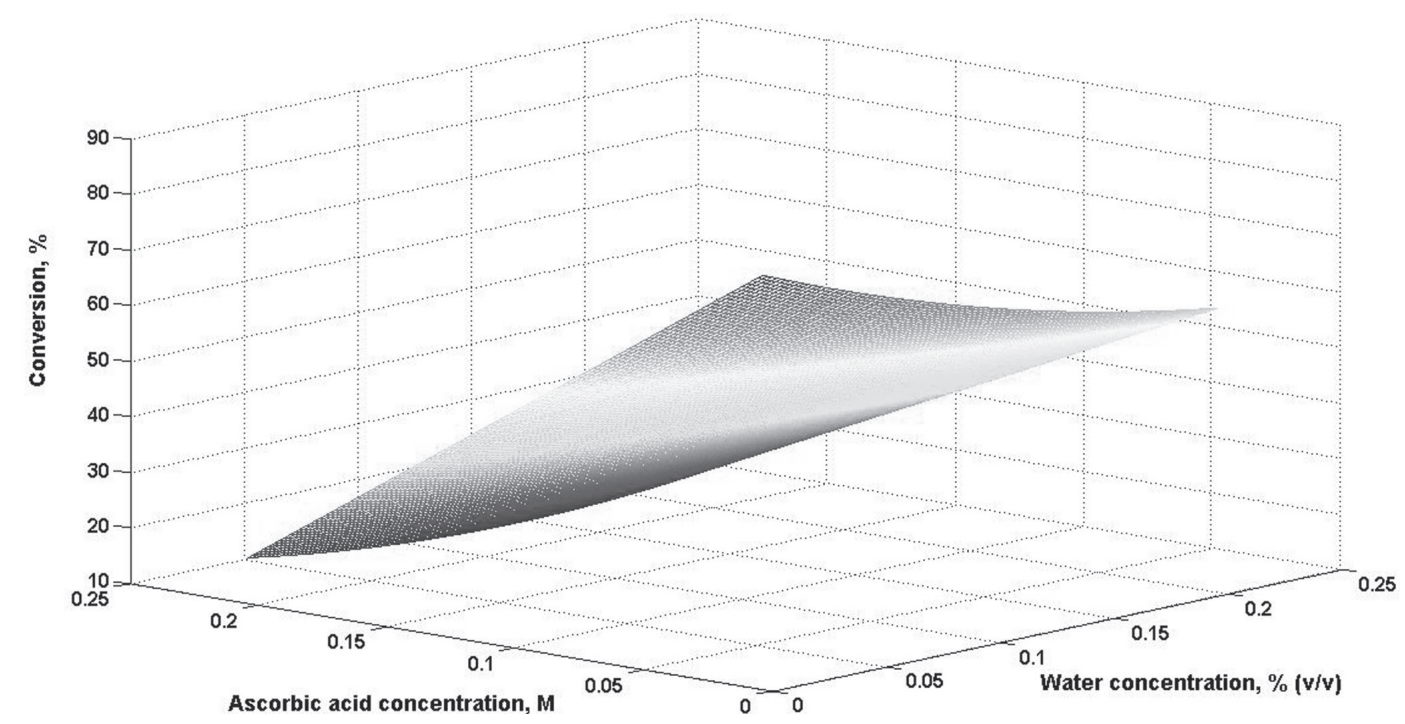

Fig. 1 The response surface of water concentration and ascorbic acid concentration effects on conversion of limiting substrate. 


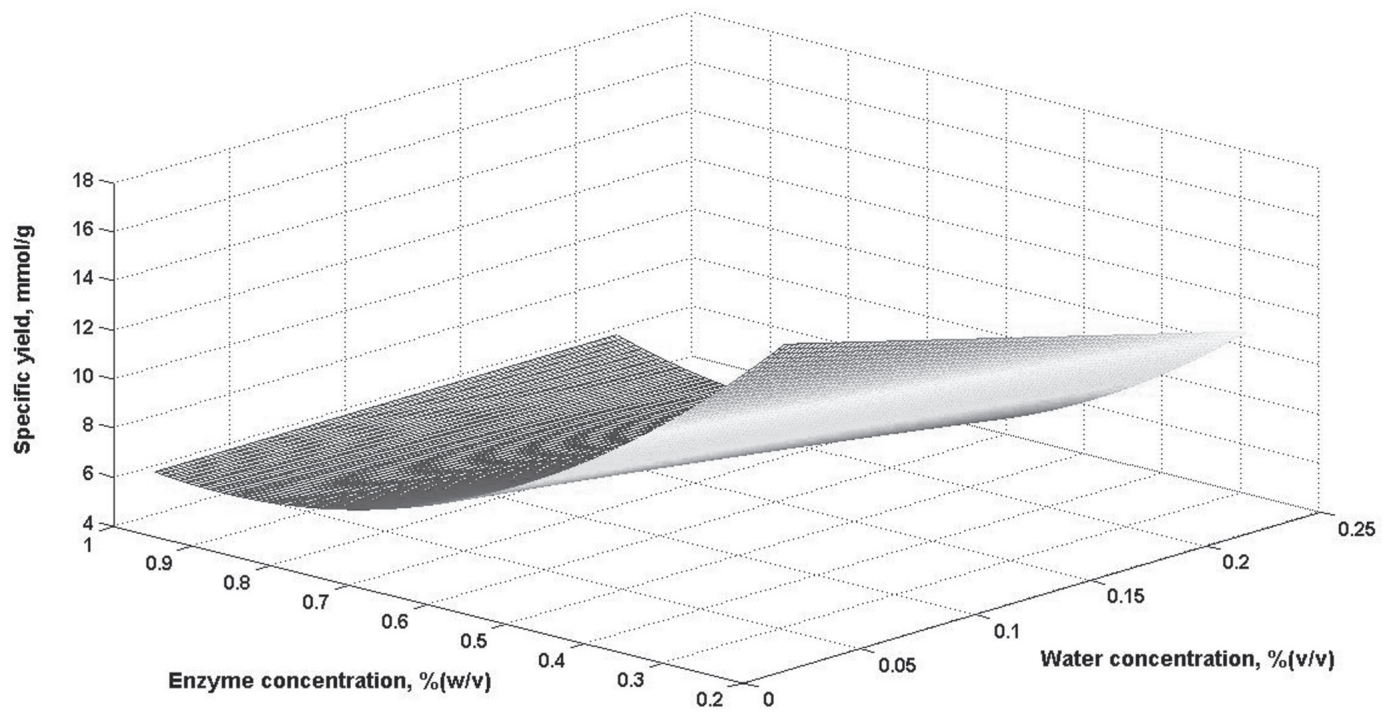

Fig. 2 The response surface of water concentration and enzyme concentration effects on specific yield of product.

water layer with primary function of preservation of open active site conformation ${ }^{31}$.

3.1.2 Enzyme loading effect

It is well-known fact that the price of the enzyme is the most important constituent in the overall expenses of the process, but reduction of the reaction time can also significantly decrease energy consumption and increase total time productivity. Therefore, one of main goals of optimization of enzymatic processes is to determine optimum concentration that will represent good compromise between these opposing demands. In previously reported RSM optimizations, conversion of vitamin C(limiting substrate) was mainly used as targeted output ${ }^{12,23-25)}$. In our opinion, important progress could be made with selection of adequate cost function, hence we also examined specific product yield (calculated as amount of ester produced per mass of consumed lipase) as output value since it contains information about both, product yield and spent enzyme amounts.

After statistical analysis it was concluded that lipase concentration did not exhibit any effect on limited substrate conversion and product yield (Eqs. 2 and 3). On the other hand, lipase concentration was significant factor for specific product yield with maximum at low concentrations (Fig. 2).

The range of lipase concentration was set to be $0.2-1.0 \%$ based on literature survey of previously reported ascorbyl ester synthesis. It seems that the lowest applied enzyme concentration was sufficient with respect to conversion and product yield, hence further increase of concentration did not make statistically observable impact on these outputs. Consequently, the increase of lipase concentration led to steep decrease of specific product yield (Fig. 2), since denominator of this expression was increasing rapidly, while numerator changed only slightly.
Generally, lipases capable of ascorbyl ester synthesis are very rare, hence enzyme preparation used in our study (Novozyme $^{\circledR} 435$ ) was used in majority of reported studies, ${ }^{2,10,12,13,24)}$ so comparison with results is simple. Applied enzyme concentrations were usually high, up to $2 \%(\mathrm{w} / \mathrm{v})$. In a several studies the effect of enzyme amount was optimized, with simple one-factor at the time variation ${ }^{2,16)}$ or using $\operatorname{RSM}^{12,23-25)}$ and obtained values were in range $0.18-1 \%(\mathrm{w} / \mathrm{v})^{2,12,16,23-25)}$. When our results are compared with optimums obtained in previous researches conducted using statistical design in which different ascorbyl esters were synthesized, it can be noticed that amount of biocatalyst consumed in our research $(0.2 \%)$ is among lowest reported values. This indicates that excessive consumption of enzyme is not necessary for achieving high productivity of lipase-catalyzed ester synthesis.

3.1.3 The effect of substrates concentrations

Effects of initial substrates concentrations were examined by varying two reaction factors: initial concentration of vitamin $\mathrm{C}$ (limiting substrate) and substrate molar ratio. Both factors were found to be significant with respect to all of examined output values, but optimum values and contributions of individual coefficients differed with output.

In Eq. 2 the individual effect of vitamin $\mathrm{C}$ concentration $\left(\mathrm{x}_{5}\right)$ was described solely with negative linear coefficient, hence the highest conversion was achieved at the lowest concentration-0.02 M(Fig. 3a). The effect of molar ratio $\left(\mathrm{x}_{4}\right)$ was also represented with negative quadratic coefficient $(-1.47)$, so influence of this factor is graphically described with function with maximum. Negative interaction between these factors exists $\left(\beta_{45}=-3.7\right)$ leading to shift of local maximums, hence the highest yields are expected at molar ratio 1:15 (Fig. 3b).

On the other hand, in Eqs. 3 and 4 quadratic coefficient 

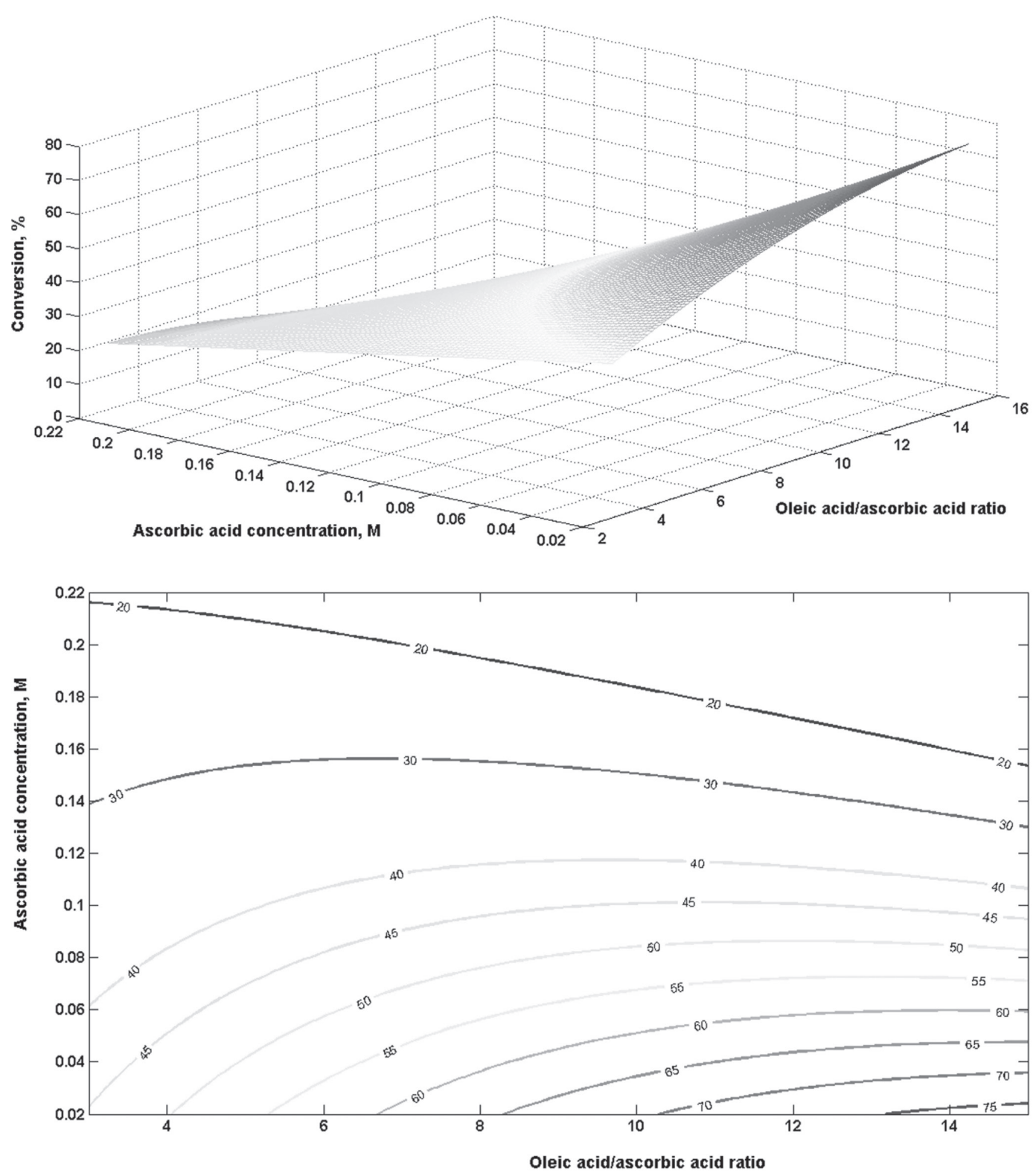

Fig. 3 Effects of ascorbic acid concentration and substrates molar ratio on conversion. a) Response surface plot; b) Contour plot.

for effect of vitamin $C\left(\beta_{44}\right)$ was also significant with negative value, so the influence of this factor was not straight forward and output values reached maximum within observed scope(Figs. 4 and 5 ). The negative interaction factor between vitamin $\mathrm{C}$ concentration and molar ratio $\left(\beta_{45}\right)$ participates in both models with different intensity, which slightly affected positions of output maximums. Therefore, maximum of predicted product yield was achieved at $0.13 \mathrm{M}$ vitamin $\mathrm{C}$ and substrate molar ratio 1:9 (Fig. 4b), while specific product yield reached maximum at $0.135 \mathrm{M}$ and 1:8(Fig. 5b). Generally, optimums for these outputs are similar, but significantly differ from optimums for conversion degree indicating that significantly higher ascorbic acid concentrations are beneficial for outputs describing overall process productivity, than for its maximum conversion. On the other hand, optimum molar ratios obtained in our study were lower for product yield and specific product yields, than for conversion degree. It seems that it could be ascribed to negative interaction between molar ratio and vitamin $\mathrm{C}$ concentration. Therefore, with yields as outputs, optimum vitamin $\mathrm{C}$ concentration was higher leading to decrease of molar ratios optimum. Similar trend of decrease of product yield caused by the increase of acyl donor concentration above certain limits was previously reported and ascribed to conformational changes of lipase induced by excess of lipid in organic phase which 

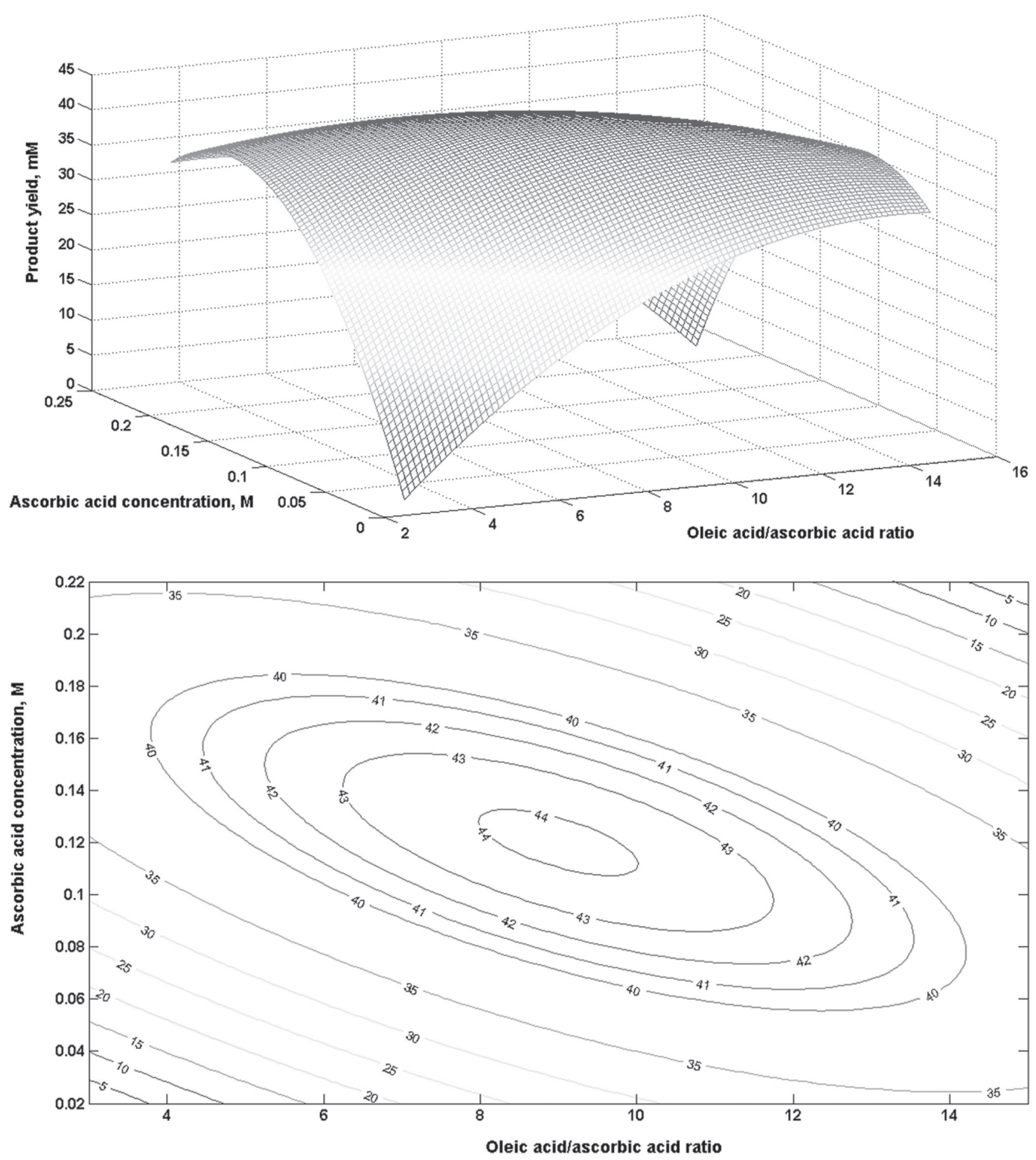

Fig. 4 Effects of ascorbic acid concentration and substrates molar ratio on product yield. a) Response surface plot; b) Contour plot.

caused hindered access of the hydrophilic ascorbic acid to the catalytic site of the enzyme ${ }^{2)}$. In general, excessive amounts of acyl donors were used in lipase-catalyzed synthesis of esters of vitamin $\mathrm{C}$, which is in accordance with our results. However, in esterification of L-ascorbic acid and benzoic acid in cyclohexanone optimized using RSM, equimolar conditions ( $0.1031 \mathrm{M}$ of both substrates) were applied $^{25)}$.

When it comes to vitamin $\mathrm{C}$ concentration, it can be concluded that in researches with aim of molar conversion maximization, lower concentrations were applied (usually up to $0.1 \mathrm{M})^{13,19,24)}$, while in studies in which output was product yield, higher amounts of L-ascorbic acid were used (above $0.1 \mathrm{M})^{2,10,16)}$. Only a few authors optimized limiting substrate concentration in terms of ester yield ${ }^{25,32,33)}$. Similar trends were observed in study of ascorbyl oleate synthesis by Kuwabara et al., since at lower concentrationslinear increase of ester yield with increase of L-ascorbic acid concentration was observed at all molar ratios, while at higher vitamin $\mathrm{C}$ concentrations and higher molar ratios, only small increase of product yield was noted ${ }^{32)}$. Yang and coworkers obtained maximum yield of ascorbyl-conjugated linoleic acid ester at highest investigated concentrations of vitamin $\mathrm{C}(0.28 \mathrm{M})$, but synthesis was performed at high lipase concentration, hence specific product yield is significantly higher in our study ${ }^{33)}$.

High yield at moderate molar excess of oleic acid obtained in our study is very beneficial for further process 

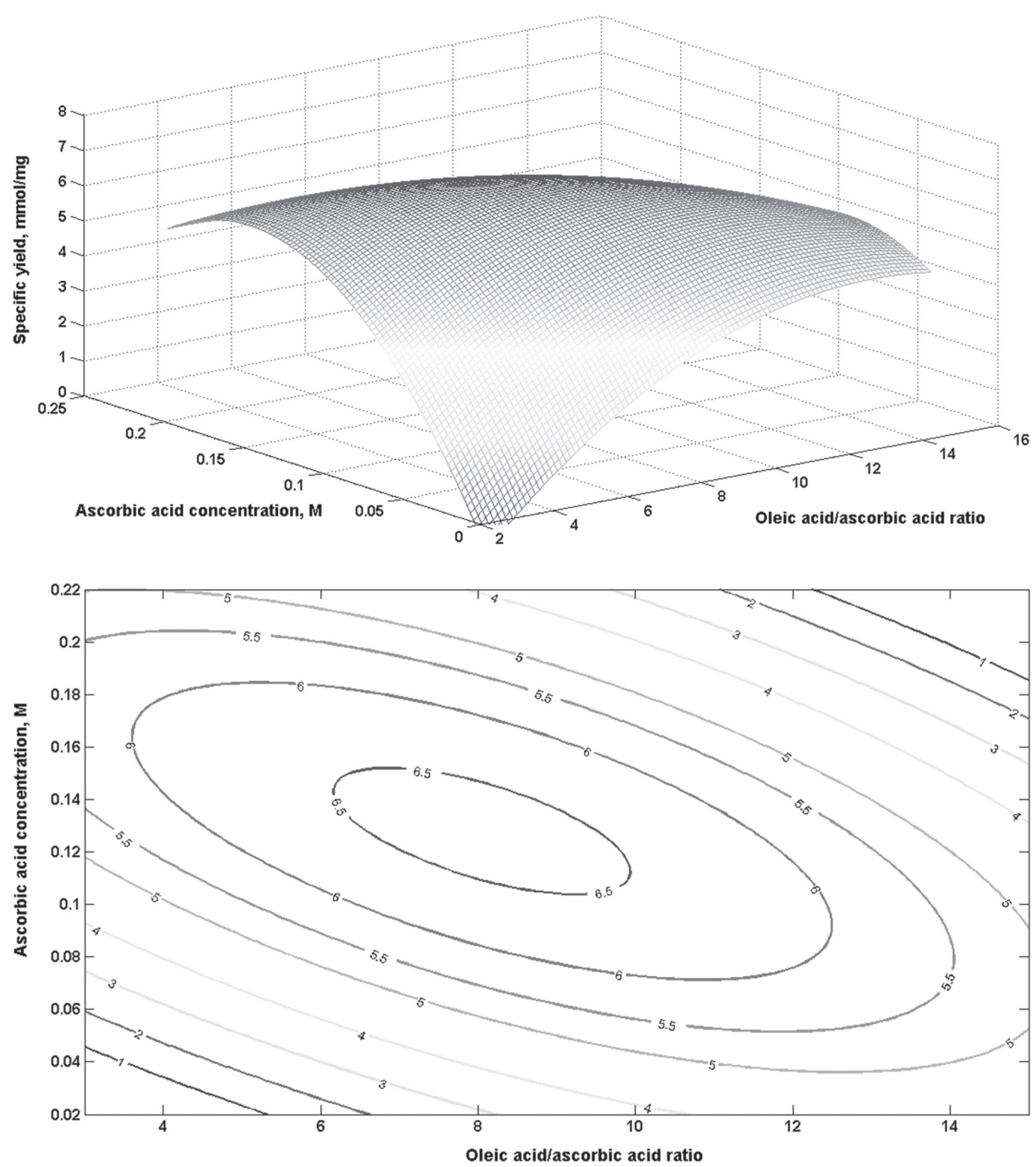

Fig. 5 Effects of ascorbic acid concentration and substrates molar ratio on specific product yield. a) Response surface plot; b) Contour plot.

development since it reduces the concentration of nonconsumed oleic acid in final reaction mixture and simplifies downstream processing.

3.1.4 The effect of reaction temperature

The effects of temperature are similar with respect to each of examined outputs, since in obtained models (Eqs. 2-4) linear and quadratic coefficients are significant with positive values. In Fig. 6 the influence of temperature is depicted and it can be seen that output maximums were reached at $60^{\circ} \mathrm{C}$. It should be noted that boiling point of acetone is $\sim 56^{\circ} \mathrm{C}$, but due to colligative properties of analyzed solutions, liquid reaction mixtures could be obtained up to $60^{\circ} \mathrm{C}$. Therefore, examination of temperatures above $60^{\circ} \mathrm{C}$ would be futile since reaction medium becomes gaseous due to high volatility of acetone.

In previous reports, for different acyl donors and organic solvents, temperatures ranging from $30^{\circ} \mathrm{C}$ to $70^{\circ} \mathrm{C}$ were established as optimal. In a synthesis of the same ester performed with immobilized lipase from Candida sp. the highest initial rates were accomplished at $60^{\circ} \mathrm{C}$, and maximum ascorbyl oleate concentration was achieved at $55^{\circ} \mathrm{C}^{16)}$. In a two separated investigations of ascorbyl palmitate synthesis using same lipase preparation as in our study high yields were reported at $55^{\circ} \mathrm{C}^{10)}$ and $60^{\circ} \mathrm{C}^{13)}$. Interestingly, in optimization study using same lipase preparation in synthesis of ascorbyl laurate temperature optimum as 


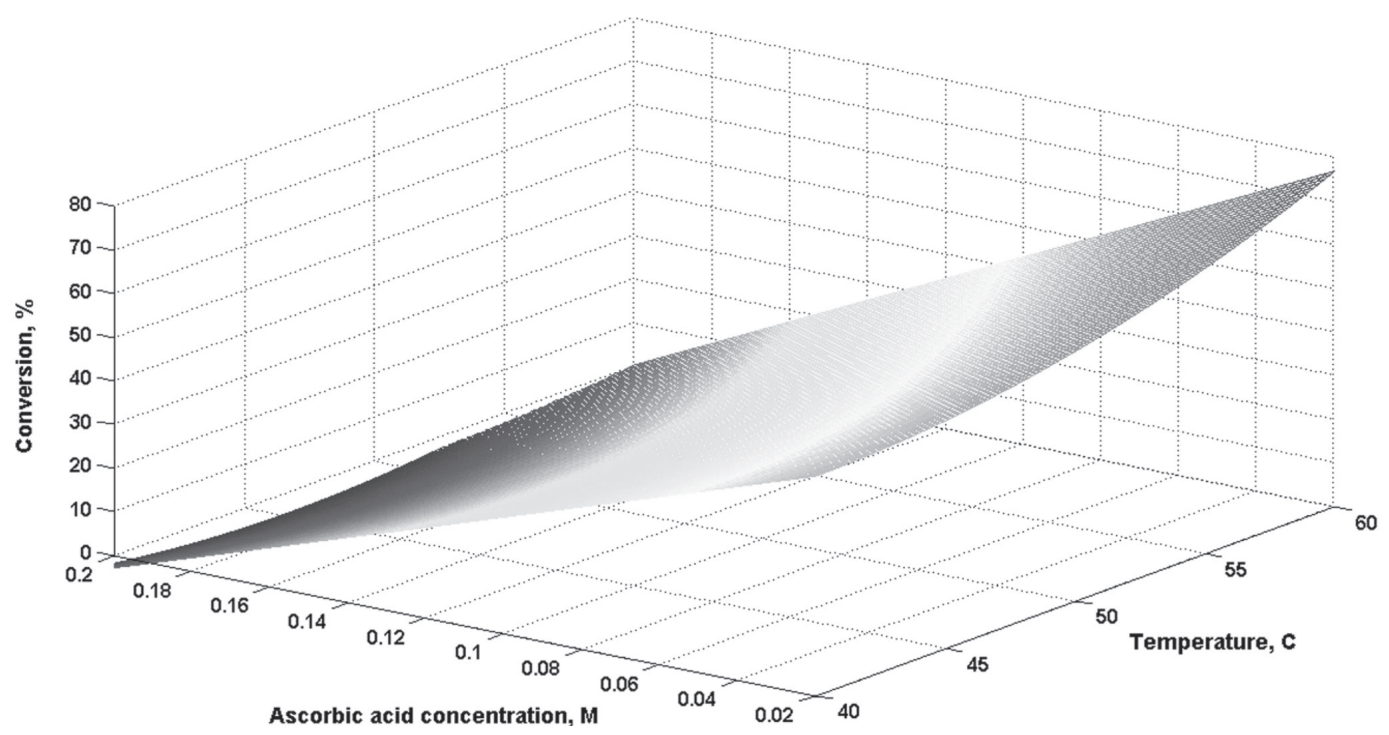

Fig. 6 The response surface of temperature and ascorbic acid concentration effects on limiting substrate conversion.

low as $30.6^{\circ} \mathrm{C}$ was reported ${ }^{24)}$. On the other hand, when RSM and CCD were applied for optimization of lipase-catalyzed synthesis of ascorbyl palmitate and ascorbyl benzoate, significantly higher optimums $\left(70^{\circ} \mathrm{C}\right.$ and $66.63^{\circ} \mathrm{C}$, respectively) were obtained ${ }^{12,25)}$. Large discrepancies between values obtained in various studies indicate that temperature optimum is strongly affected by properties of substrates, product, and solvent.

\subsubsection{Evaluation of model prediction}

The goodness of model prediction was tested at optimum values with regard to specific product yield. At optimum reaction conditions predicted maximum yield was 17.2 mmol g ${ }^{-1}$, higher than the highest obtained yield-in experiment No. 22. Accuracy of model prediction was confirmed with additional experiment performed at optimum conditions in which $16.7 \mathrm{mmol} \mathrm{g}^{-1}$ was achieved, which is only $2.9 \%$ deviation from predicted value. Moreover, specific yields obtained in our experiments are significantly higher than those achieved in previous syntheses of ascorbyl esters conducted in acetone $-3.6 \mathrm{mmol} \mathrm{g}^{-117}$.

\subsection{The effect of molecular sieves addition on specific product yield}

Since water is product of esterification, the optimization of initial water concentration is not sufficient to provide high reaction yields. Therefore, influence of water removal by addition of molecular sieves, was investigated. The addition of molecular sieves in reaction mixture enables continuous removal of water and shifting thermodynamic equilibrium towards higher yields of ester ${ }^{15,16)}$. Nevertheless, in several studies was noticed that if sieves are added too early they can absorb essential water and destroy catalytic conformation of enzyme ${ }^{34,35)}$. Therefore, the timing of addition of sieves was also analyzed (Fig. 7). It can be seen that

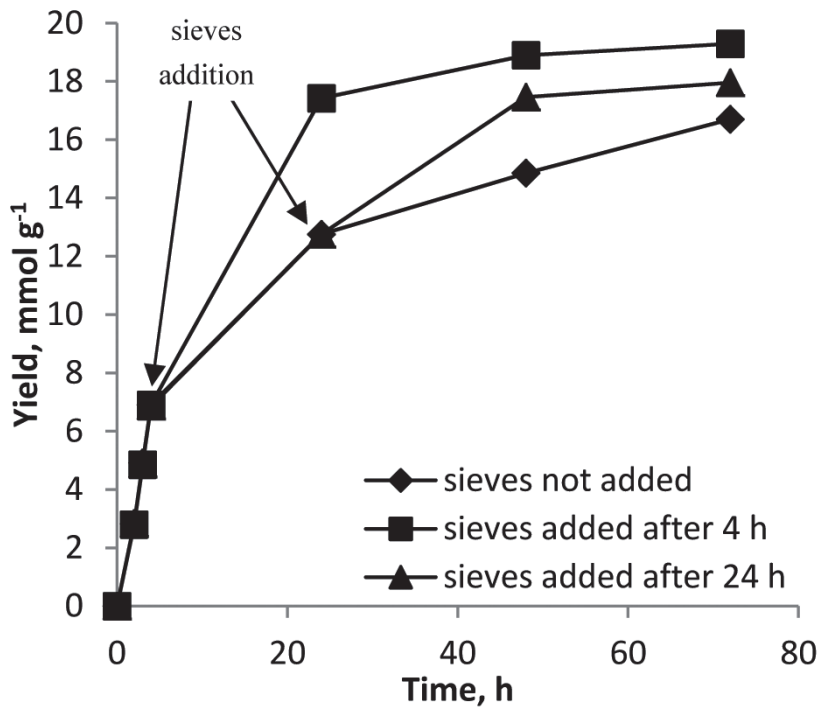

Fig. 7 Influence of molecular sieves. The reactions were carried out at $60^{\circ} \mathrm{C}$ for $72 \mathrm{~h}$, with $0.135 \mathrm{M}$ of vitamin $\mathrm{C}$ and $1.08 \mathrm{M}$ of oleic acid, with 0.2 $\%(\mathrm{w} / \mathrm{v})$ of lipase and $0.018 \%(\mathrm{v} / \mathrm{v})$ of water in $10 \mathrm{~mL}$ of reaction medium, with $50 \mathrm{mg} \mathrm{mL}^{-1}$ of molecular sieves (if added).

ester yields were significantly improved by addition of adsorbent. The effect of sieves was more pronounced when addition was performed in $4^{\text {th }}$ hour of reaction. After comparison of the shapes of reaction curves, it can be noticed that after $4 \mathrm{~h}$ significant decrease of reaction rate occurs if sieves were not added. On the other hand, after addition of sieves in $4^{\text {th }}$ hour esterification continues with almost unchanged rate for around $20 \mathrm{~h}$ resulting with product yield increase to $19.3 \mathrm{mmol} \mathrm{g}^{-1}$. 


\subsection{Reusability study and biocatalyst reactivation}

The utilization of immobilized biocatalyst in repeated reaction cycles and monitoring the retained activity offers good estimation of prospects for development of enzymatic ascorbyl oleate synthesis. The change of immobilized lipase activity throughout ten reaction cycles, lasting 24 hours, is illustrated in Fig. 8. During initial five cycles activity of lipase was constant or even increased. Subsequently stable inactivation occurred leading to preservation of $48 \%$ of initial activity after ten cycles.

Previous reports containing data about operational activity of lipases has been prevalently focused on synthesis of aliphatic esters ${ }^{36,37-39)}$. Generally, it can be noticed that stability predominantly depends on the amount of hydrophilic organic compounds, which can have role of solvent or substrate. Very illustrative is example of isoamyl acetate synthesis in $n$-heptane catalyzed with Lipozyme where at high substrate concentrations lipase activity was completely diminished at equimolar conditions after only 4 cycles, while at excess of alcohol (less hydrophilic substrate) lipase activity reduced only about $10 \%$ in ten cycles ${ }^{37)}$. Similar or even higher rate of Novozyme ${ }^{\circledR} 435$ deactivation than in our study was observed in synthesis of butyl isobutyrate in $n$-heptane since activity was reduced to around $70 \%$ of initial activity after five cycles, or in citronellyl laurate synthesis in same solvent was reduced to around 90\% after only three cycles ${ }^{22,38)}$. Higher stability of same immobilized lipase preparation was observed only in study of solventfree synthesis of ethyl docosahexanoate, but reaction was performed at significantly lower temperature $-30^{\circ} \mathrm{C}^{39)}$. Therefore, observed operational stability in our study is satisfying since observed retention of activity was similar to above mentioned studies, although it was performed in

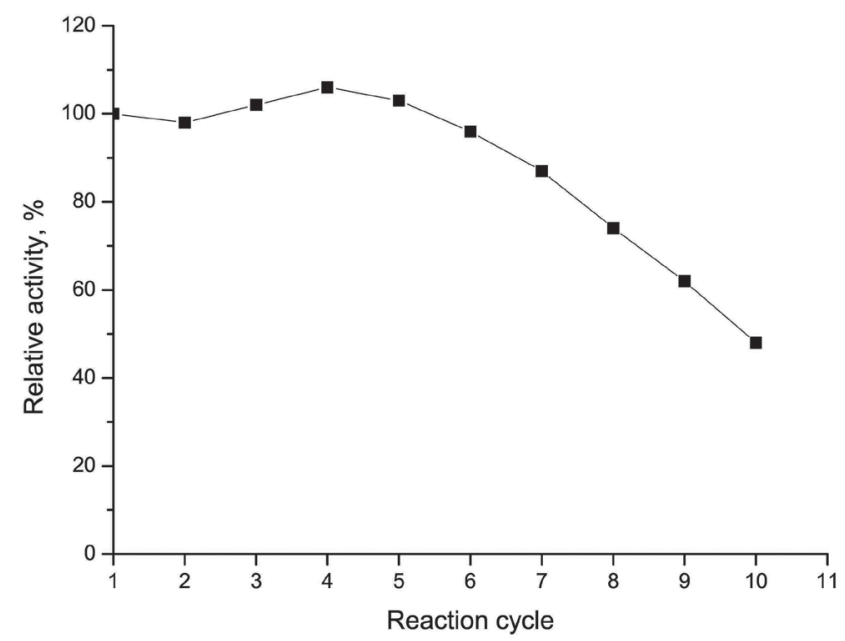

Fig. 8 Change of immobilized lipase activity throughout ten reaction cycles, lasting 24 hours. The reactions were carried out at previously optimized conditions. very polar organic solvent (acetone), which usually favor faster inactivation of lipase.

Overall yield obtained after ten reaction cycles with one batch of immobilized lipase was $153 \mathrm{mmol} \mathrm{g}^{-1}$. Finally, attempt was made to reactivate partially inactivated immobilized lipase obtained after $10^{\text {th }}$ reaction cycle. It was previously stated that in presence of organic solvents lipase inactivation occurs predominantly due to distortion of its three dimensional structure ${ }^{40)}$. If immobilized preparation is also subjected to high temperatures chemical modifications can also occur ${ }^{40)}$. Since it was previously shown that reactivation can be achieved in some extent with simple incubation in phosphate buffer with or without added detergents, we tested this strategy on our sample ${ }^{40,41)}$. After incubation in $50 \mathrm{mM}$ phosphate buffer lipase activity increased to $72 \%$ of initial (in $1^{\text {st }}$ reaction cycles). It seems that applied strategy ensures at least partial reactivation of immobilized lipase and offers possibility of prolonged usage of lipase preparation and reduction of production costs.

\subsection{Structural analysis}

The product was isolated using semi preparative HPLC column and NMR spectra were determined: ${ }^{1} \mathrm{H}$ NMR $(200$ $\left.\mathrm{MHz}, \mathrm{CDCl}_{3}\right) \delta 5.34(2 \mathrm{H}), \delta 4.77(1 \mathrm{H}), \delta 4.32(1 \mathrm{H}), \delta 4.20$ $(2 \mathrm{H}), \delta 2.35(2 \mathrm{H}), \delta 2.02(4 \mathrm{H}), \delta 1.60(2 \mathrm{H}), \delta 1.28(20 \mathrm{H}), \delta$ $0.88(3 \mathrm{H})$. The characteristic functional groups were confirmed with ${ }^{13} \mathrm{C}\left(50 \mathrm{MHz}, \mathrm{CDCl}_{3}\right)$ : (CO-O ester $170.05 \mathrm{ppm}$; CO 174.20 ppm; enolic C 154.15 and 118.36 ppm; $\mathrm{CH}=\mathrm{CH}$ $130.00 \mathrm{ppm}$ ). Spectral analysis confirmed that compound is identical with oleoyl L-ascorbic acid ${ }^{16)}$.

\section{CONCLUSION}

In this study, key reaction factors of lipase-catalyzed ascorbyl oleate synthesis in acetone were optimized using response surface methodology (RSM) and 5-level-5-factor central composite rotatable design (CCRD) with respect to three different outputs. Temperature and water concentration exhibited equal optimums, $60^{\circ} \mathrm{C}$ and $0.018 \%(\mathrm{v} / \mathrm{v})$, with respect to all examined outputs, but discrepancies were observed in analysis of effects of lipase concentration and substrates concentration. It was found out that maximum specific product yields (in mmol of product per $\mathrm{g}$ of lipase) was achieved at lowest examined values of lipase concentration $-0.2 \%(\mathrm{w} / \mathrm{v}), 0.135 \mathrm{M}$ of vitamin $\mathrm{C}$, and substrates molar ratio 1:8. Obtained specific product yield (16.7 mmol $\left.\mathrm{g}^{-1}\right)$ was promising in comparison with previous literature reports, hence further experiments with purpose of developing cost-effective enzymatic process were performed at optimum values for this output. Since reaction equilibrium of ester synthesis can be shifted towards product formation by water removal subsequent experimental series was focused on optimization of molec- 
ular sieve addition in reaction mixture, and further increase to $19.3 \mathrm{mmol} \mathrm{g}^{-1}$ was achieved by addition of molecular sieves at $4^{\text {th }}$ hour of esterification. Enzyme reusability study indicated that over $80 \%$ of initial activity was retained throughout seven reaction cycles and it was shown that simple procedure of partial lipase reactivation with phosphate buffer made process much more productive. Obtained yields are comparable with previously reported yields obtained with more expensive solvents and/or complex acyl donors, indicating that enzymatic synthesis in acetone offers good prospect for developing cost-effective enzymatic process.

\section{ACKNOWLEDGEMENTS}

The authors are grateful for financial support from Serbian Ministry of Education, Science, and Technological Development (project III 46010).

\section{References}

1) Karmee, S. K. Biocatalytic synthesis of ascorbyl esters and their biotechnological applications. Appl. Microbiol. Biotechnol. 81, 1013-1022 (2009).

2) Burham, H.; Rasheed, R. A. G. A.; Noor, N. M.; Badruddin, S.; Sidek, H. Enzymatic synthesis of palm-based ascorbyl esters. J. Mol. Catal. B: Enzym. 58, 153-157 (2009).

3) Yan, Y.; Bornscheuer, U. T.; Schmid, R. D. Lipase-catalyzed synthesis of vitamin C fatty acid esters. Biotechnol. Lett. 21, 1051-1054(1999).

4) Karmee, S. K. Lipase catalyzed synthesis of esterbased surfactants from biomass derivatives. Biofuel. Bioprod. Bior. 2, 144-154(2008).

5) Karmee, S. K. The synthesis, properties, and applications of ascorbyl esters. Lipid Technol. 23, 227-229 (2011).

6) Moribe, K.; Limwikrant, W.; Higashi, K.; Yamamoto, K. Drug Nanoparticle Formulation Using Ascorbic Acid Derivatives. Journal of Drug Delivery. doi:10.1155/ 2011/138929 (2011).

7) Kobayashi, T.; Takahashi, T.; Adachi, S. Synthesis of 6-O-octanoyl-1,2-O-isopropylidene- $\alpha$-D-glucofuranose by Lipase-catalyzed Esterification in Organic Solvent. J. Oleo Sci. 61, 75-79(2012).

8) Ali, A.; Kaur, M.; Mehra, U. Use of Immobilized Pseudomonas sp. as Whole Cell Catalyst for the Transesterification of Used Cotton Seed Oil. J. Oleo Sci. 60, 7-10 (2011).

9) Al Mulla, E. A. J. Lipase-Catalyzed Synthesis of Fattythioic Acids from Palm Oil. J. Oleo Sci. 60, 41-45 (2011).
10) Humeau, C.; Girardin, M.; Rovel, B.; Miclo, A. Effect of the Thermodynamic Water Activity and the Reaction Medium Hydrophobicity on the Enzymatic Synthesis of Ascorbyl Palmitate. J. Biotechnol. 63, 1-8(1998).

11) Humeau, C.; Girardin, M.; Ravel, B.; Miclo, A. Enzymatic Synthesis of Fatty Acid Ascorbyl Esters. J. Mol. Catal. B: Enzym. 5, 19-23(1998).

12) Lerin, L. A.; Richetti, A.; Dallaro, R.; Treichel, H.; Mazutti, M. A.; Oliveira, J. V.; Antunes, O. A. C.; Oestreicher, E. G.; Oliveira, D. Enzymatic Synthesis of Ascorbyl Palmitate in Organic Solvents: Process Optimization and Kinetic Evaluation. Food Bioprocess Technol. 5, 1068-1076 (2012).

13) Viklund, F.; Alander, J.; Hult, K. Antioxidative Properties and Enzymatic Synthesis of Ascorbyl FA Esters. J. Am. Oil. Chem. Soc. 80, 795-799 (2003).

14) Reyes-Duarte, D.; Lopez-Cortes, N.; Torres, P.; Comelles, F.; Parra, J. L.; Peña, S.; Ugidos, A. V.; Ballesteros, A.; Plou, F. J. Synthesis and Properties of Ascorbyl Esters Catalyzed by Lipozyme TL IM using Triglycerides as Acyl Donors. J. Am. Oil. Chem. Soc. 88, 57-64 (2011).

15) Bradoo, S.; Saxena, R. K.; Gupta, R. High yields of ascorbyl palmitate by thermostable lipase-mediated esterification. J. Am. Oil. Chem. Soc. 76, 1291-1295 (1999).

16) Song, Q.-X.; Wei, D.-Z.; Study of Vitamin C ester synthesis by immobilized lipase from Candida sp. J. Mol. Catal. B: Enzym. 18, 261-266 (2002).

17) Adamczak, M.; Bornscheuer, U. T. Improving ascorbyl oleate synthesis catalyzed by Candida antarctica lipase $\mathrm{B}$ in ionic liquids and water activity control by salt hydrates. Process Biochem. 44, 257-261 (2009).

18) Park, S.; Viklund, F.; Hult, K. M.; Kazlauskas, R. J. Vacuum-driven lipase-catalyzed direct condensation of Lascorbic acid and fatty acids in ionic liquids: synthesis of a natural surface active antioxidant. Green Chem. 5, 715-719(2003).

19) Adamczak, M.; Bornscheuer, U. T.; Bednarski, W. Synthesis of ascorbyl oleate by immobilized Candida antarctica lipases. Process Biochem. 40, 3177-3180 (2005).

20) Cochran, W. G.; Cox, G. M. Experimental designs, $2^{\text {nd }}$ ed. Wiley, New York, USA (1992).

21) Hamsaveni, D. R.; Prapulla, S. G.; Divakar, S. Response surface methodological approach for the synthesis of isobutyl isobutyrate. Process Biochem. 36, 1103-1109 (2001).

22) Chiang, W.-D.; Chang, S.-W.; Shieh, C.-J. Studies on the optimized lipase-catalyzed biosynthesis of cis-3hexen-1-yl acetate in $n$-hexane. Process Biochem. 38, 1193-1199 (2003).

23) Zhao, H.; Zhang, Y.; Lu, F.; Bie, X.; Lu, Z.; Ning, H. Optimized enzymatic synthesis of ascorbyl esters from 
lard using Novozym 435 in co-solvent mixtures. $J$. Mol. Catal. B: Enzym. 69, 107-111(2011).

24) Chang, S.-W.; Yang, C.-J.; Chen, F.-Y.; Akoh, C.-C.; Shief, C.-J. Optimized synthesis of lipase-catalyzed Lascorbyl laurate by Novozym ${ }^{\circledR} 435$. J. Mol. Catal. B: Enzym. 56, 7-12 (2009).

25） Lv, L.-X.; Chen, S.-Y.; Li, Y.-Q. Study of lipase-catalyzed synthesis of ascorbyl benzoate in cyclohexanone using response surface methodology. J. Sci. Food Agric. 88, 659-666 (2008).

26) Hsieh, H.-J.; Chen, J.-W.; Giridhar, R.; Wu, W.-T. Synthesis of Mixed Esters of Ascorbic Acid Using Methyl Esters of Palm and Soybean Oils. Prep. Biochem. Biotech. 35, 113-118(2005).

27) Chen, J.-P. Production of Ethyl Butyrate Using GelEntrapped Candida cylindracea lipase. J. Ferment. Bioeng. 82, 404-407 (1996).

28) Ognjanović, N.; Bezbradica, D.; Knežević-Jugović, Z. Enzymatic Conversion of Sunflower Oil to Biodiesel in a Solvent-free System: Process Optimization and the Immobilized System Stability. Bioresource Technol. 100, 5146-5154 (2009).

29) Salis, A.; Pinna, M.; Monduzzi, M.; Solinas, V. Biodiesel Production from Triolein and Short Chain Alcohols through Biocatalysis. J. Biotechnol. 119, 291-299 (2005).

30) Tamalampudi, S.; Talukder, M. R.; Hama, S.; Numata, T.; Kondo, A.; Fukuda, H. Enzymatic production of biodiesel from jatropha oil: a comparative study of immobilized-whole cell and commercial lipases as a biocatalyst. Biochem. Eng. J. 39, 185-189 (2007).

31) Martinek, K.; Semenov, A.; Berezin, I. Enzymatic synthesis in biphasic aqueous-organic systems. I. Chemical equilibrium shift. Biochim. Biophys. Acta. 658, 76-89 (1981).

32) Kuwabara, K.; Watanabe, Y.; Adachi, S.; Nakanishi, K.; Matsuno, R. Synthesis of 6-O-unsaturated acyl l-ascorbates by immobilized lipase in acetone in the presence of molecular sieve Biochem. Eng. J. 16, 17-22 (2003) .

33) Yang, Z.; Schultz, L.; Guo, Z.; Jacobsen, C.; Xu, X. Sys- tem Development from Organic Solvents to Ionic Liquids for Synthesizing Ascorbyl Esters with Conjugated Linoleic Acids. Open Biotech. J. 6, 5-12 (2012).

34) Monot, F.; Borzeix, M.; Bardin, M.; Vandecasteele, P. Enzymatic Esterification in Organic Media: Role of Water and Organic Solvent in Kinetics and Yield of Butyl Butyrate Synthesis. Appl. Microbiol. Biotechnol. 35, 759-765 (1991).

35) Stojaković, S.; Bezbradica, D.; Mijin, D.; Knežević, Z.; Šiler-Marinković, S. Influence of Zeolites and Silica Gel on the Synthesis of Amyl Isobutyrate Catalyzed by Candida rugosa Lipase. Chem. Ind. 62, 64-68 (2008).

36) Yadav, G. D.; Lathi, P. S. Synthesis of citronellol laurate in organic media catalyzed by immobilized lipases: kinetic studies. J. Mol. Catal. B: Enzym. 27, 109-115 (2004).

37) Hari Krishna, S.; Divakar, S.; Prapulla, S. G.; Karanth, N. G. Enzymatic synthesis of isoamyl acetate using immobilized lipase Rhizomucor miehei. J. Biotechnol. 87, 193-201(2001).

38) Yadav, G. D.; Lathi, P. S. Kinetics and mechanism of synthesis of butyl isobutyrate over immobilized lipases. Biochem. Eng. J. 16, 245-252 (2003).

39) Shimada, Y.; Watanabe, Y.; Sugihara, A.; Baba, T.; Ooguri, T.; Moriyama, S.; Terai, T.; Tominaga, Y. Ethyl esterification of Docosahexaenoic Acid in an Organic Solvent-Free System with Immobilized Candida antarctica lipase. J. Biosci. Bioeng. 92, 19-23 (2001).

40) Rodrigues, R. C.; Bolivar, J. M.; Palau-Ors, A.; Volpato, G. Positive effects of the multipoint covalent immobilization in the reactivation of partially inactivated derivatives of lipase from Thermomyces lanuginosus. Enzyme Microb. Technol. 44, 386-393 (2009).

41) Godoy, C. A.; de las Rivas, B.; Bezbradica, D.; Bolivar, J. M.; Lopez-Gallego, F.; Fernandez-Lorente, G.; Guisan, J. M. Reactivation of thermostable lipase by solid phase unfolding/refolding. Effect of cysteine residues on refolding efficiency. Enzyme Microb. Technol. 49, 388-394(2011). 